\title{
Asymmetric Draw-Tower Tapers for Supercontinuum Generation and Verification of the Novel Concept of Group-Acceleration Matching
}

Sørensen, Simon Toft; Møller, Uffe; Moselund, P. M. ; Jakobsen, C.; Johansen, J.; Andersen, T. V. ; Thomsen, C. L.; Bang, Ole

Published in:

CLEO Technical Digest

Publication date:

2012

Document Version

Publisher's PDF, also known as Version of record

Link back to DTU Orbit

Citation (APA):

Sørensen, S. T., Møller, U., Moselund, P. M., Jakobsen, C., Johansen, J., Andersen, T. V., Thomsen, C. L., \& Bang, O. (2012). Asymmetric Draw-Tower Tapers for Supercontinuum Generation and Verification of the Novel Concept of Group-Acceleration Matching. In CLEO Technical Digest (pp. QM4E.4). Optical Society of America.

\section{General rights}

Copyright and moral rights for the publications made accessible in the public portal are retained by the authors and/or other copyright owners and it is a condition of accessing publications that users recognise and abide by the legal requirements associated with these rights.

- Users may download and print one copy of any publication from the public portal for the purpose of private study or research.

- You may not further distribute the material or use it for any profit-making activity or commercial gain

- You may freely distribute the URL identifying the publication in the public portal 


\title{
Asymmetric Draw-Tower Tapers for Supercontinuum Generation and Verification of the Novel Concept of Group- Acceleration Matching
}

\author{
S.T. Sørensen ${ }^{1}$, U. Møller ${ }^{1}$, P.M. Moselund ${ }^{2}$, C. Jakobsen ${ }^{2}$, J. Johansen ${ }^{2}$, \\ T.V. Andersen ${ }^{2}$, C.L. Thomsen ${ }^{2}$, and O. Bang ${ }^{1,2}$ \\ ${ }^{I}$ DTU Fotonik, Department of Photonics Engineering, Technical University of Denmark, 2800 Kgs. Lyngby, Denmark \\ ${ }^{2}$ NKT Photonics A/S, Blokken 84, DK-3460, Birkerød, Denmark \\ Corresponding author: stso@fotonik.dtu.dk
}

\begin{abstract}
We present the first short asymmetrical draw-tower photonic crystal fiber taper for maximizing the power in the blue edge of a supercontinuum. The results clearly emphasize the importance of the taper shape on the spectrum.

OCIS codes: (060.4370) Nonlinear Optics, fibers; (320.6629) Supercontinuum generation.
\end{abstract}

\section{Introduction}

Since its discovery supercontinuum (SC) generation has spawned intense research in nonlinear optics of both fundamental and applied nature, and the field has now reached a point of maturity where commercial SC sources are available. The focus has hence turned to stabilizing the spectrum and extending the spectral bandwidth into the UV region below $400 \mathrm{~nm}$ motivated by commercial potentials in areas such as fluorescent microscopy [1]. In this work, we present the first short asymmetrical photonic crystal fiber (PCF) taper fabricated directly on the draw-tower. The fiber is tapered back to its initial diameter to facilitate better handling and coupling efficiency, and to allow for an investigation of the asymmetry. We demonstrate efficient SC generation with extended bandwidth and, based on our recent work [2], we give a clear interpretation of the results and provide a recipe for optimizing the taper shape for maximum bandwidth and available power in the blue edge of the spectrum.

In the high-power long-pulse pumping regime, an SC spectrum largely consists of a solitonic red edge linked to a dispersive wave (DW) blue edge through a complex trapping mechanism. As the solitons are redshifting they cause the DWs to blueshift in a manner dictated by group-velocity $(\mathrm{GV})$ matching $[3,4]$. Tapering provides a way of altering the GV profile of the fiber, and hence the link between the spectral edges [2,5]. In a uniform fiber a soliton can trap and blueshift a DW as long as it keeps redshifting and decelerating. However, when a soliton and trapped DW enter a taper, the soliton undergoes a relatively larger change in GV (deceleration), which diminishes the trapping potential and causes light to escape. The trapping process and leakage is illustrated in Fig. 1 with a careful numerical simulation of the propagation of a soliton and seeded DW through a tapered fiber; the DW clearly starts shedding light in the tapered part of the fiber. In our recent numerical paper [2], we coined the taper induced relative change in GV as the Group-Acceleration Mismatch (GAM), and demonstrated that more light is blueshifted when the GAM is minimised by making the down-tapering more gradual. This can be understood as an enhancement of the interaction between the soliton and DW due to a minimization of the walk-off.

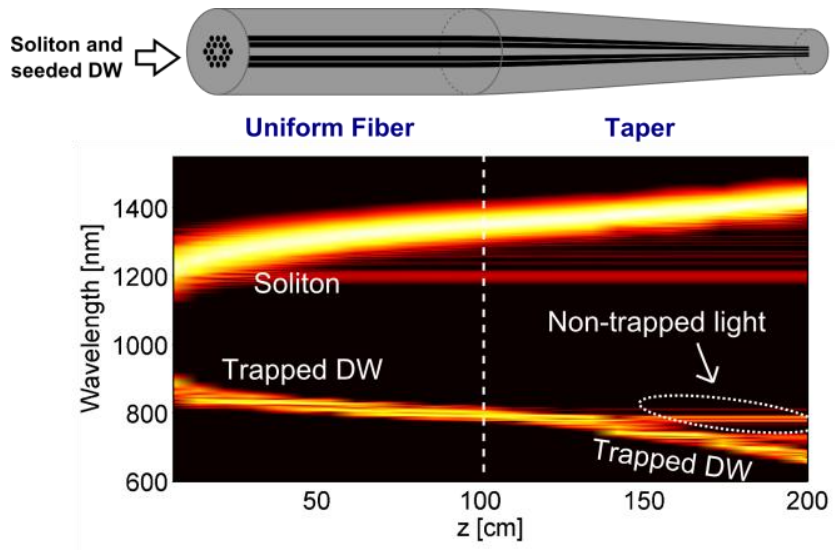

Fig. 1. Numerical simulation of a $20 \mathrm{fs}$ soliton and seeded DW through a taper with an initial $1 \mathrm{~m}$ uniform fiber: Spectral evolution of the two pulses through the taper. The DW is trapped at the taper entrance, but the taper causes light to leak from the trapping region due to GAM. 


\section{Experiments}

In continuation of our findings, we fabricated an asymmetric photonic crystal fiber (PCF) taper directly on the drawtower. Tapering directly on the draw-tower offers unprecedented control of the fiber parameters and excellent reproducibility. A characterization of the taper's coating diameter is shown in Fig. 2(a); the change in coating diameter was found to be in agreement with the change in fiber pitch (hole spacing) calculated from cross-sectional images, and the structure was fully preserved throughout the tapered section.

The asymmetry of the taper allows for a straightforward investigation of the impact of taper steepness on the power in the blue edge by pumping the fiber from either side. Fig. 2(b) shows the spectra obtained when pumping the fiber with a $1064 \mathrm{~nm}$ ps laser and compares the spectra obtained when pumping from the short and long downtapering side of the taper with that of a uniform fiber of a similar length, and the results are clear: tapering yields a clear extension of the spectral bandwidth, and pumping from the long down-tapering side significantly enhances the available power in the extended bandwidth as expected due to the lower GAM. The taper had $5 \mathrm{~m}$ uniform fiber before and after the tapered section.

(a) Taper characterisation

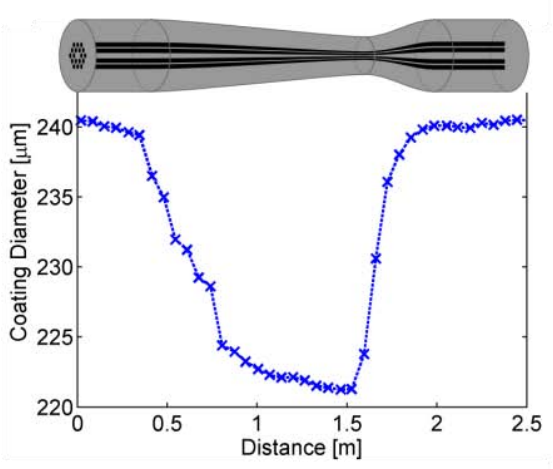

(b) Output spectra

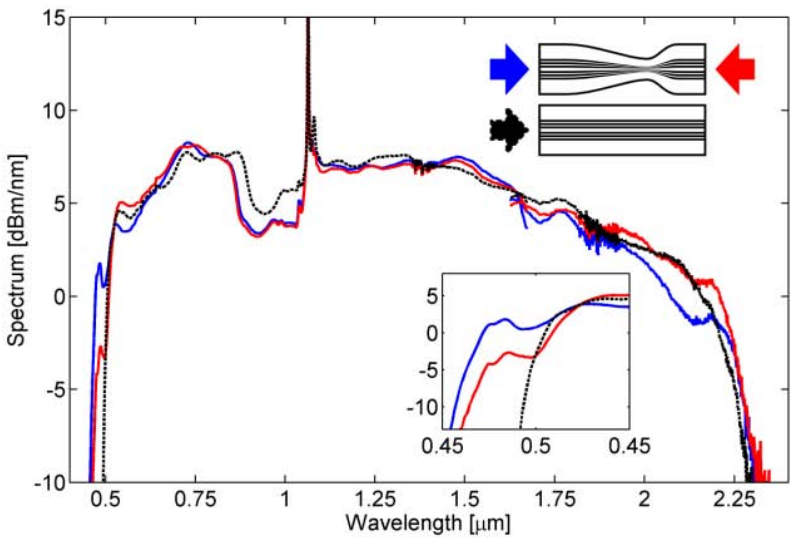

Fig. 2. (a) Profile of the asymmetric draw-tower taper determined by the coating diameter measured on the draw-tower. The structure was maintained throughout the taper. (b) Experimental spectra when pumping the taper from the long (blue) and short (red) down-taped sides. The spectrum from a $10 \mathrm{~m}$ uniform fiber (black dash) is shown for comparison. The insets show a schematic of the pump directions and a close up of blue-edge, respectively. Pumping from the long down-tapering side clearly gives more power in the blue edge. The fibers were pumped at 1064 $\mathrm{nm}$ with $10 \mathrm{ps}$ pulses at $14 \mathrm{~W}$ average power and $80 \mathrm{MHz}$ rep. rate.

Combined with the results in [5], it is thus possible to tailor at least the blue edge of the spectrum: the bandwidth is controlled by fixing the GV matching to a given wavelength, whereas the power is controlled by the length and shape of the down-tapered section. For long tapers the fiber attenuation must be expected to start counteracting the gain at short wavelengths.

At the conference we will present further measurements of other tapers and discuss the limitations.

\section{Conclusion}

In conclusion, we fabricated the first short asymmetric draw-tower taper and verified the importance of our novel concept of group-acceleration matching (GAM) to find the optimal taper shape. Specifically, it was demonstrated that the taper shape has a strong impact on the resulting spectrum, i.e., a longer down-tapered section yields a higher power in the blue edge of the spectrum due to a correspondingly lower GAM.

[1] A. Kudlinski, M. Lelek, B. Barviau, L. Audry, and A. Mussot, "Efficient blue conversion from a $1064 \mathrm{~nm}$ microchip laser in long photonic crystal fiber tapers for fluorescence microscopy," Opt. Express 18, 16640-16645 (2010).

[2] S.T. Sørensen, A. Judge, C. Thomsen, and O. Bang, "Optimum fiber tapers for increasing the power in the blue edge of a supercontinuum group-acceleration matching," Opt. Lett. 36, 816-818 (2011).

[3] A.V. Gorbach, D.V. Skryabin, J.M. Stone, J.C. Knight, "Four-wave mixing of solitons with radiation and quasi-nondispersive wave packets at the short-wavelength edge of a supercontinuum", Opt. Express 14, 9854 (2006).

[4] A. V. Gorbach and D. V. Skryabin, "Light trapping in gravity-like potentials and expansion of supercontinuum spectra in photonic-crystal fibres," Nature Photonics 1, 653 - 657 (2007).

[5] J.C. Travers, "Blue extension of optical fibre supercontinuum generation," Journal of Optics 12, 113001 (2010). 